Artikel Penelitian

\title{
Sistem Deteksi Cepat Mutu Organoleptik Beras Berbasis Android
} Rapid Detection System for Organoleptic Quality of Rice using the Android Application

Agus Supriatna Somantri, Maulida Hayuningytas, Nikmatul Hidayah, Hoerudin, Mulyana Hadipernata*

Balai Besar Penelitian dan Pengembangan Pascapanen Pertanian, Badan Penelitian dan Pengembangan Pertanian, Bogor

*Korespondensi dengan penulis (mulya_nata@yahoo.com)

Artikel ini dikirim pada tanggal 19 Maret 2020 dan dinyatakan diterima tanggal 3 September 2020. Artikel ini juga dipublikasi secara online melalui https://ejournal2.undip.ac.id/index.php/jatp. Hak cipta dilindungi undang-undang. Dilarang diperbanyak untuk tujuan komersial.

Diproduksi oleh Indonesian Food Technologists® @2020

\begin{abstract}
Abstrak
Penelitian ini bertujuan untuk mengembangkan alat deteksi cepat mutu organoleptik beras berbasis pada pemanfaatan aplikasi Android agar pengujian mutu organoleptik beras dapat dilakukan secara cepat dan akurat. Bahan penelitian yang digunakan adalah beras varietas Ciherang dan Tarabas. Metode yang digunakan adalah dengan menggunakan realtime image processing berbasis Android dan Java. Hasil penelitian menunjukkan bahwa lamanya penyimpanan beras sangat mempengaruhi citra beras (Red Green Blue/RGB). Selama penyimpanan beras, nilai Blue menghasilkan nilai perubahan yang nyata dibandingkan nilai Red dan Green. Nilai Blue ini berkorelasi positif terhadap perubahan kadar amilosa selama penyimpanan dan mutu organoleptiknya. Aplikasi deteksi cepat mutu organoleptik beras juga telah berhasil dibuat dan dapat diuji validitasnya dengan memperhatikan perubahan karakateristik citra, perubahan amilosa, dan mutu organoleptiknya. Kesimpulannya, aplikasi deteksi cepat ini berhasil dikembangkan dengan berbasis Android yang dapat digunakan sebagai alat uji mutu organoleptik beras.
\end{abstract}

Kata kunci: beras, mutu organoleptik, deteksi cepat, image processing, Android

\begin{abstract}
The research was aimed at developing rapid detection tool of rice upon organoleptic quality based on the Android application, so the testing may be done quickly and accurately. Ciherang and Tarabas rice varieties were used in this research. Realtime image processing based on Android and Java were used as method in this research. The results showed that the storage affected the rice image value (Red Green Blue/RGB). During storage, the value of the blue (B) produced a proper marked which was positively correlated to the changes in amylose content. Application of rapid detection of organoleptic quality of rice was carried out by observing changes in image characteristics, changes in amylose, and changes in organoleptic properties. As conclusion, the application may functioning properly and can be used as a tool to test the organoleptic quality of rice and its shelf life.
\end{abstract}

Keywords: rice, organoleptic quality, fast detection, image processing, android

\section{Pendahuluan}

Beras merupakan pangan pokok masyarakat Indonesia yang dibudidayakan dengan varietas dan jenis yang bervariasi dan akibatnya, mutu beras dari setiap varietas dapat berbeda-beda, terlebih lagi adanya proses penanaman, panen, pengangkutan dan pengolahan yang dapat membawa dampak pada tingkat kemurnian, kualitas, dan nilai produk (Kuo et al., 2016). Identifikasi mutu beras saat ini masih dilakukan dengan mengandalkan indra penglihatan sehingga dapat menyebabkan penilaian yang subjektif, oleh karena itu perlu adanya pengembangan teknologi agar dapat mengetahui kualitas beras secara lebih obyektif, misalnya penggunaan analisis gambar dengan teknik warna (Wright et al., 2009).

Mutu beras dapat dikategorikan dalam empat kelompok yang meliputi: (1) mutu fisik, (2) mutu tanak atau organoleptik, (3) mutu gizi, dan (4) standar spesifik untuk penampakan dan kemurnian biji (Permentan 31, 2017). Semua kategori mutu tersebut secara bersamaan memegang peranan penting dalam penetapan kriteria mutu beras yang sesuai dengan penggunaannya. Klasifikasi mutu fisik beras terutama ditentukan oleh ukuran biji, derajat sosoh, derajat beras pecah/beras kepala dan butir mengapur, disamping juga ditentukan oleh butir merah, gabah, dan butir rusak (SNI 6128:2015). Penurunan kualitas beras dapat berupa penurunan volume, kerusakan fisik, biokimiawi dan mikrobiologi (Hadipernata et al., 2020; Vanna and Bundit, 2007), sehingga mempengaruhi penampakan beras, perubahan tekstur, rasa dan aroma nasi. Faktor utama penyebab kerusakan selama penyimpanan adalah kadar air, suhu, dan lama penyimpanan, sedangkan kadar air menjadi faktor yang paling menentukan kerusakan beras (Bhattacharya, 2011). Selain itu pengujian mutu beras dapat dilakukan dengan menganalisis kandungan pati yang didefinisikan sebagai polimer glukosa bercabang yang terdiri dari dua jenis molekul: amilopektin dan amilosa (Robyt, 2008). Molekul amilopektin sangat bercabang dengan sejumlah besar pendek cabang dengan bobot molekul relatif besar yaitu $1 \times 10^{6}$ sampai $5 \times 10^{8}$ Da sedangkan amilosa memiliki molekul yang relatif lebih kecil yaitu berkisar 162.000 sampai 648.000 Da dengan $3-10$ cabang yang dapat dijadikan sebagai indikator kualitas beras (Gilbert et al., 2013).

Teknologi image processing yang telah berkembang sejak tahun 1960 dapat diaplikasikan untuk deteksi mutu beras (Narendra and Hareesh 2010). Teknologi tersebut digunakan untuk mengetahui 
karakteristik mutu produk pangan dan pertanian secara visual, dan termasuk dalam pengujian yang non destruktif (Timmermans, 1998). Kegunaan utama dari image processing adalah dapat mendeteksi kerusakan akibat green mould pada jeruk, dan teknologi yang berkembang dapat memperbaiki tingkat validasi dari 65 menjadi 94\% dengan menggunakan image fluorescens (Blasco, 2007). Teknik sortasi buah delima dengan Bayesian Linear Discriminant Analysis (LDA) dalam rentang Red Green Blue (RGB) juga dinilai memberikan hasil validasi yang cukup tinggi, yaitu mencapai $90 \%$ (Blasco, 2009).

Pendekatan analisa mutu beras berbasis foto atau gambar lebih cepat dilakukan tanpa merusak beras dan telah banyak diterapkan untuk membedakan varietas biji-bijian sereal dengan menggunakan salah satu dari sifat morfologis, warna, dan tekstur atau kombinasi dari sifat-sifat tersebut (Putranto et al., 2010; Kuo et al., 2016). Terdapat beberapa kegiatan dari hasil penelitian dengan teknik berbasis image processing di industri makanan untuk penilaian mutunya (Pattel et al., 2012). Neelamegam et al. (2013) menilai teknik image processing pada butiran beras varietas Basmati India dinilai mempunyai akurasi yang lebih tinggi dari penginderaan manusia. Hal ini dapat dijelaskan bahwa teknik image processing dapat menelusuri suatu obyek dengan tepat, cepat, dan mampu menelusuri tingkat kesulitan yang tinggi pada obyek (Ahmed et al., 2005). Selain pada beras, teknik image processing juga dapat diterapkan untuk menduga kadar air pada padi selama proses pengeringan (Hung and Chern, 2012).

Kategori mutu pada beras dinilai sangat luas, sehingga diperlukan deteksi komprehensif pada mutu beras yang sesuai kebutuhan dengan kategori mutu secara parsial. Akurasi klasifikasi untuk beberapa studi mengenai beras cukup bervariasi, sehingga untuk menentukan tingkat mutu perlu adanya panduan untuk tingkat kerusakan secara komprehensif dan sampai saat ini masih sedikit sekali dokumentasi mengenai penelitian ini. Keberadaan beras juga tidak bisa dilepaskan dengan masa simpannya, oleh karena itu deteksi mutu beras perlu dilakukan secara komprehensif khususnya untuk mendapatkan perhitungan yang tepat dan efisien (Chen et al., 2019). Berdasarkan penjelasan tersebut, penelitian ini bertujuan untuk mengembangkan alat deteksi cepat mutu beras berbasis pada pemanfaatan teknologi image processing yang kemudian dikembangkan dengan menggunakan sistem Android yang nantinya dapat sebagai alat pengujian mutu beras secara cepat dan akurat.

\section{Materi dan Metode}

Materi

Bahan yang digunakan adalah beras varietas Ciherang dan Tarabas yang diperoleh dari daerah Karawang, Jawa Barat. Bahan kimia yang digunakan untuk pengujian kadar amilosa beras yaitu $\mathrm{NaOH}$, ethanol, methanol, KI, dan standar amilosa (potato amylose) yang semuanya adalah reagent grade. Bahan pendukung lainnya adalah bahan rekayasa yang meliputi akrylik dengan ketebalan $5 \mathrm{~mm}$ dan bahanbahan pembantu lainnya untuk membuat media pengamatan secara khusus. Smartphone yang digunakan adalah jenis Samsung Galaxy J7 plus yang dipergunakan sebagai alat untuk pengambilan keputusan tentang mutu beras yang diuji.

\section{Metode}

Rekayasa Medium Pemindaian Beras

Rekayasa ini dilakukan dengan mengikuti prosedur peneliti sebelumnya (Somantri, 2010) yang dilakukan untuk membuat kotak citra sebagai tempat untuk pemindaian citra beras. Perekayasaan meliputi perancangan, pembuatan komponen, perakitan, dan pengujian. Kotak citra dibuat sedemikian rupa sehingga bisa dengan mudah dioperasikan dan dibersihkan. Pada bagian dalam dari kotak citra dilengkapi dengan lampu led sebagai sarana penerangan untuk sampel beras yang diuji, dan sebagai tempat sample holder yang dengan mudah untuk dapat dioperasikan.

\section{Pengumpulan Data Image}

Beras dalam karung plastik sebanyak $30 \mathrm{~kg}$ disimpan dalam ruangan yang terkontrol selama 5 bulan. Pengamatan dilakukan terhadap perubahan karakteristik citra, kadar amilosa, dan mutu organoleptiknya. Pengambilan sampel dilakukan satu kali dalam sebulan sebanyak 5 kali pengulangan. Data yang dikumpulkan meliputi data warna Red Green Blue atau RGB dari hasil pemindaian citra beras setiap butiran beras dengan jumlah sebanyak 500 butir untuk model penduga amilosa dan 500 sampel butir beras untuk validasi. Pemindaian citra dilakukan dengan kamera 8 mega pixel dengan mode pengaturan lensa secara manual. Citra beras diambil dengan latar belakang berwarna hitam untuk mempermudah proses thresholding dan cropping.

\section{Real Time Image Processing}

Real time image processing adalah teknologi untuk membuat perangkat lunak yang dipergunakan untuk melakukan pengujian karakterisasi citra pada sampel beras. Karakteristik citra yang dibangkitkan dalam penelitian ini adalah RGB diperoleh dari tiap-tiap pixel warna pada citra butir beras yang merupakan nilai intensitas untuk masing-masing warna merah, hijau, dan biru. Karakteristik citra yang diperoleh nantinya dicari korelasinya dengan hasil uji amilosa dari laboratorium dan hasil uji organoleptiknya. Secara operasional tahapan kegiatan kegeiatan penelitian pengembangan alat deteksi cepat mutu organoleptik beras dapat dilihat pada Figur 1 dan dilaksanakan dengan mengadopsi peneliti sebelumnya (Effendi et al., 2017). Seluruh operasi pembuatan aplikasi untuk system deteksi mutu organoleptik dilakukan dengan menggunakan sistem pemrograman Android 3.5.1 dengan Java. Aplikasi ini dirancang sedemikian rupa sehingga semua pengguna dari aplikasi ini dapat menggunakannya secara mudah dan cepat. 


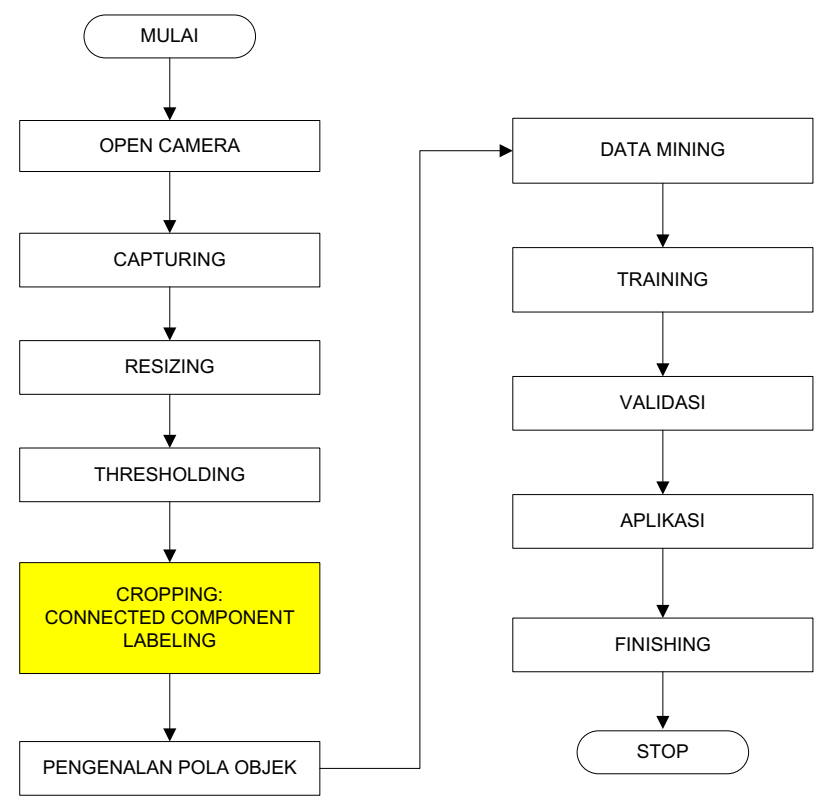

Figur 1. Flowchart penelitian pengembangan deteksi cepat mutu organoleptik beras berbasis Android pada smartphone

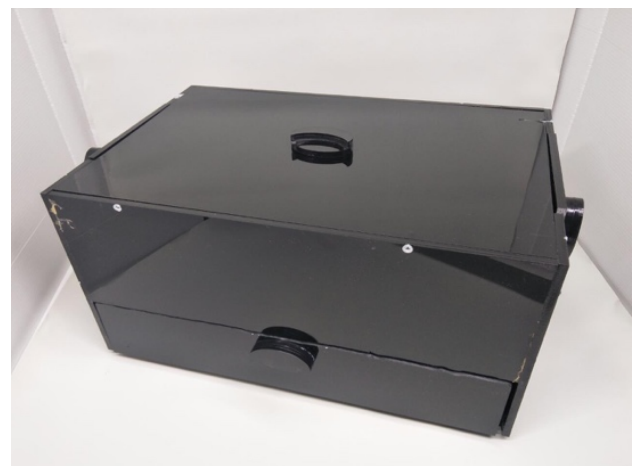

Figur 2. Box image untuk tempat pemindaian citra beras

\section{Pembuatan Perangkat Keras}

Perangkat keras dimaksud ialah berupa kotak atau box image yang berfungsi untuk pengambilan citra berdasarkan warna yang ditimbulkan dari butir beras ditunjukkan pada Figur 2 sesuai dengan prosedur dari peneliti sebelumnya (Somantri, 2010). Perangkat box image dilengkapi dengan lampu led yang berasal dari kamera smartphone. Lampu led berfungsi untuk menerangi sample beras pada sample holder, dan dengan menggunakan lampu led ini citra beras diharapkan dapat ditangkap oleh kamera dengan hasil

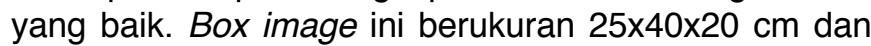
berwarna hitam agar tidak menimbulkan pantulan cahaya yang tidak diinginkan pada hasil akhir.

\section{Instalasi Program Android}

Beberapa software digunakan dalam pengembangan program dalam deteksi cepat mutu beras, diantaranya software dalam pemrograman Android image processing yaitu Open CV. Software ini sangat memudahkan dalam mengerjakan teknik pengenalan pola dan karakteristik image secara kuantitatif. Basis pemrograman menggunakan software Android Studio 3.5.1, software tambahan yang dibutuhkan yaitu software Software Development Kit
(SDK) dan Application Package File (APK) yang merupakan extensi untuk program aplikasi Android sesuai dengan prosedur standar pembuatan aplikasi dari Android. Melalui penggunaan software tambahan ini maka sistem pemrograman dapat dibuat sistem aplikasinya sehingga pengguna dapat mudah aksesnya.

\section{Desain Program Antar Muka}

Penyusunan desain antar muka dapat ditetapkan masing-masing tipe data dalam setiap kolom desain tersebut, meliputi layar kamera, tombol pengaktifan kamera dan tombol proses. Open kamera adalah langkah awal ketika tombol kamera digunakan, maka kamera smartphone langsung terhubung dan siap untuk melakukan pemindaian objek (beras) yang diuji. Selanjutnya di-klik tombol OK dan sistem dapat memproses dan kemudian menekan tombol "PROSES", untuk selanjutnya program secara otomatis melakukan tahapan proses termasuk proses perhitungan untuk menentukan tingkat kelayakan konsumsi beras serta dugaan kandungan amilosa.

\section{Pengukuran Kadar Amilosa}

Pengujian kadar amilosa beras dilakukan pada beras varietas Tarabas dan varietas Ciherang. Beras ini diperoleh dari gabah yang digiiing di Rice Milling Unit (RMU) yang ada di Laboratorium Mutu Beras dan Pascapanen Serealia Karawang. Beras ini kemudian disimpan di ruang penyimpanan khusus beras. Setiap bulan, sampel beras diambil dari ruang penyimpanan dan dilakukan pengujian kadar amilosa selama 5 bulan yang dilakukan secara duplo. Pengujian dengan spektrometer sesuai dengan SNI 6128 tahun 2015.

\section{Analisis Mutu Organoleptik}

Sampel beras (Tarabas dan Ciherang) dimasak menjadi nasi dengan waktu pemasakan dan jumlah air yang sama. Uji mutu organoleptik dilakukan setiap bulan selama 5 bulan dengan mengamati mutu hedoniknya. Parameter penilaian terdiri dari 5 skor penilian yang diurutkan mulai dari sangat tidak suka, tidak suka, biasa, suka dan sangat suka, masing-masing untuk skor 1 sampai 5. Analisis organoleptik meliputi warna, aroma, tekstur, dan penerimaan umum terhadap sampel nasi tersebut. Uji mutu organoleptik ini dilakukan dengan menggunakan panelis semi terlatih sebanyak 25 orang. Data yang didapat kemudian dihitung rata ratanya (Nuriana et al., 2018)

\section{Resize Image, Thresholding, dan Cropping}

Penurunan resolusi citra, telah tersedia dalam aplikasi yang dapat mereduksi ukuran gambar menjadi menjadi 640 × 480 piksel (VGA) yang selanjutnya, dilakukan thresholding untuk hanya menampilkan citra berasnya dengan latar belakang warna hitam yang kemudian dikuantifikasi. Cropping dilakukan pada setiap butir beras untuk menentukan karakteristik nilai RGB yang menggunakan sistem connected component labeling (CCL) (Cabaret et al., 2014). Setiap karakteristik citra RGB ini perlu dikenali dengan baik agar diketahui 
karateristik mana yang paling berpengaruh dalam mengenali perubahan kandungan amilosa pada beras.

\section{Analisis Data Citra}

Analisis data RGB dari pengolahan citra digital dan data amilosa serta data organoleptik ditentukan korelasinya dengan menggunakan Microsoft Excel 2016. Penentuan hubungan citra dan hasil uji laboratorium dilakukan dengan menghitung korelasi antara karakteristik citra dan uji laboratorium.

\section{Hasil dan Pembahasan}

\section{Analisis Citra RGB Beras}

Sampel beras pada penelitian ini adalah varietas Ciherang dan Tarabas yang dipilih karena kedua varietas tersebut memiliki karakteristik fisik yang jelas berbeda. Beras Ciherang bentuknya bulat memanjang sedangkan beras Tarabas bentuknya bulat (Wibawa et al., 2019). Hal tersebut disebabkan adanya perbedaan kandungan amilosa dan amilopektin pada masingmasing varietas tersebut.

Pemindaian citra pada sampel beras Ciherang dilakukan selama 5 bulan seperti ditunjukkan pada Figur 3. Citra beras sulit untuk dibedakan secara kasat mata karena bentuk dan warnanya sama, padahal untuk kepentingan penelitian dibutuhkan citra beras yang terukur karakteristiknya secara kuantitatif. Salah satu penentu kualitas beras dilihat dari nilai keseragaman warna beras hingga nilai presentase bulir beras (Supriyadi et al., 2020). Karakterisasi citra beras secara kuantitatif harus diperoleh dengan melakukan pengolahan citra yaitu dengan membangkitkan karakteristik nilai RGB-nya. Berdasarkan nilai RGB, dapat dilihat masing-masing perubahannya selama penyimpanan dan dinilai penting untuk diketahui, karena merupakan dasar dalam menentukan karakteristik citra yang paling berpengaruh dan memiliki korelasi terhadap perubahan kandungan amilosa dalam beras.

Hasil dari nilai perubahan RGB dapat membangkitkan data citra pada setiap bulan selama penyimpanan 5 bulan seperti ditunjukkan pada Figur 3 . Hal tersebut terlihat bahwa karakteristik citra R, G dan B yang memiliki pola yang berbeda-beda, dan perbedaan ini dapat disebabkan oleh perubahan kadar amilosa yang dikandungnya sebagaimana ditampilkan dalam pembahasan kadar amilosa. Perubahan citra RGB pada beras Ciherang memiliki bentuk dan pola yang berbedabeda, dan setelah dilakukan regresi linear nilai koefisien determinasinya yang terbesar adalah rata-rata nilai $B$ (Blue), yaitu 0,8127 (Figur 3a). Nilai $B$ juga berpengaruh kuat terhadap perubahan kadar amilosa. Hal ini disebabkan adanya proses oksidasi pada beras yang menyebabkan perubahan warna beras cenderung menjadi gelap dominasi warna biru (Figur 4), sehingga dapat dipastikan bahwa perubahan kandungan amilosa dalam beras berpengaruh terhadap karakteristik nilai $B$. Hasil pemindaian citra beras Tarabas ditunjukkan pada Figur 3(b), dimana nilai koefiesien regresi linearnya sebesar 0,9552 .

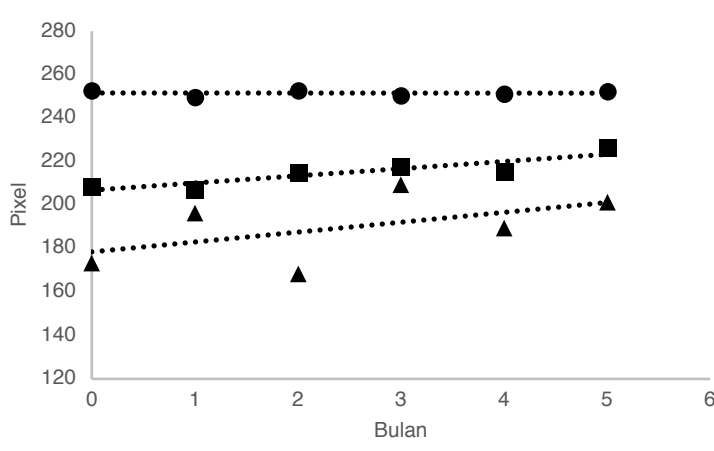

(a)

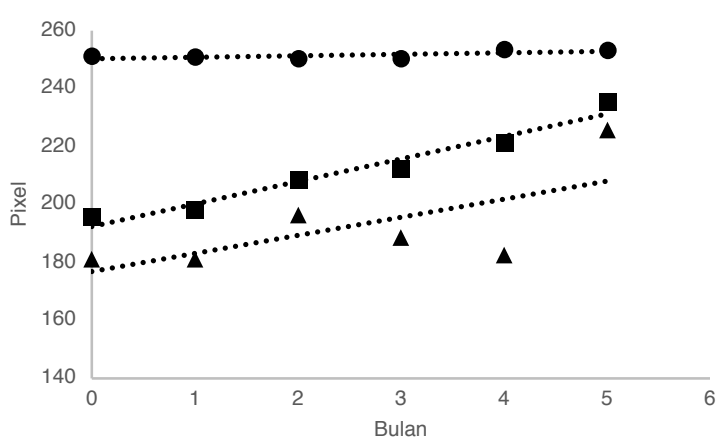

(b)

Figur 3. Citra R, G, B, (ditunjukkan dengan simbol masing masing $\mathbf{\Lambda}, \bullet, \mathbf{\square}$ ) pada beras Ciherang (a) dan Tarabas (b) selama penyimpanan 5 bulan
Ciherang 0 bulan

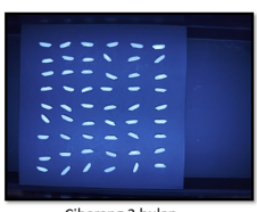

Ciherang 3 bulan

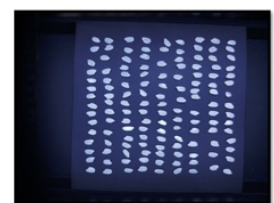

Tarabas 0 bulan

Tarabas 3 bulan
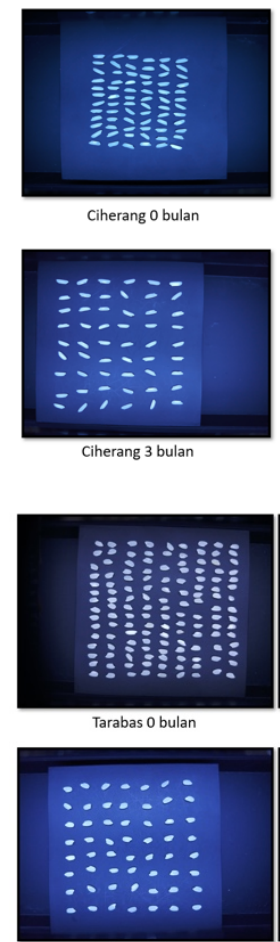

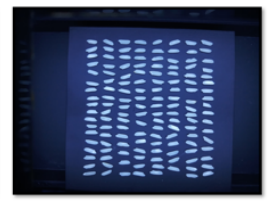

Ciherang 1 bulan

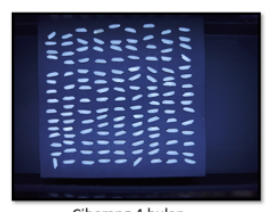

Ciherang 4 bulan

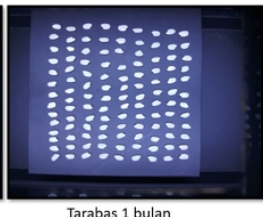

Tarabas 1 bulan

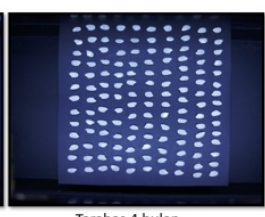

Tarabas 4 bulan

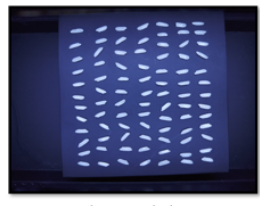

Ciherang 2 bulan

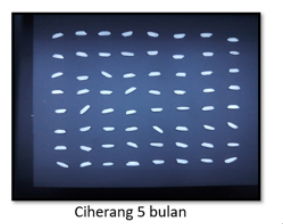

(a)
Figur 4. Tampilan beras Ciherang (a) dan Tarabas (b) selama penyimpanan 5 bulan

\section{Uji Kadar Amilosa Beras}

Kadar amilosa pada beras diujikan setap bulan bersamaan dengan pengujian citra beras. Kadar amilosa beras Ciherang menurun dari 19,03 menjadi $15,53 \%$ 
sedangkan untuk beras Tarabas, menurun dari 19,92 menjadi $15,41 \%$ selama penyimpanan 5 bulan (data tidak ditampilkan). Perubahan kadar amilosa beras Ciherang selama penyimpanan membentuk persamaan $y=-0,862 x+19,894$, dimana y adalah kadar amilosa dan $\mathrm{x}$ adalah waktu peyimpanan yang menghasilkan koefisien determinasi sebesar 0,9918 (data tidak ditampilkan), sehingga persamaan ini selanjutnya dapat dipakai sebagai alat penduga umur simpan beras Ciherang. Kadar amilosa beras Tarabas selama penyimpanan membentuk persamaan $y=-1,095 x+$ 20,293 yang menghasilkan koefisien determinasi sebesar 0,8737.

Karakteristik nilai B memiliki korelasi yang baik dengan kandungan amilosa beras Tarabas yang ditunjukkan dengan koefisien determinasinya $\left(\mathrm{R}^{2}\right)$ mencapai 0,7176 serta menghasilkan persamaan matematik y $=-0,117 x+42,053$, dimana $y=$ kadar amilosa (\%), dan $\mathrm{x}=$ nilai $\mathrm{B}$ (pixel). Pada beras Ciherang, dihasilkan persamaan matematik $y=-0,1922 x+58,899$ (data tidak ditampilkan). Dengan demikian karakteristik citra nilai B ini dapat digunakan untuk menduga perubahan kandungan amilosa beras. Pada varietas beras yang sama terdapat perbedaan kandungan amilosa karena perbedaan lama penyimpanan, semakin lama penyimpanan beras giling makan kadar amilosanya semakin naik (Sari et al., 2020). Nilai regresi dari masing-masing interaksi berlaku positif dan memiliki nilai lebih cenderung ke angka 1, yang menunjukkan bahwa lamanya penyimpanan berpengaruh pada kandungan amilosa pada beras. Penurunan kadar amilosa saat penyimpanan dapat terjadi karena tidak tepatnya perlakuan pascapanen beras dengan kriteria suhu ruangan, tingkat kelembaban ruangan, jenis varietas beras, kemasan beras, dan adanya hama gudang (Wardani et al., 2020). Penurunan amilosa merupakan salah satu kriteria untuk menentukan mutu atau mutu beras dari segi rasa, bau dan tekstur, sehingga diperlukan penanganan pascapanen beras yang tepat agar kadar amilosa dapat stabil dan masih layak konsumsi. Kandungan amilosa dalam beras berbeda-beda karena adanya perbedaan suhu, ketinggian tempat dan kelembaban daerah (Syamsiah dan Masliah, 2019).

\section{Uji Mutu Organoleptik}

Tingkat kesukaan hasil uji mutu organoleptik untuk kedua jenis beras tersebut seperti disajikan pada Figur 5 dan terlihat bahwa untuk beras Ciherang pada bulan ke-1 masih sangat disukai, pada bulan ke-2 dan 3 masih disukai, sedangkan untuk bulan ke-4 dan 5 sudah dinilai kurang disukai. Pada pengamatan secara visual, sejak bulan ke-3 sudah mulai diserang oleh kutu atau hama Gudang (data tidak ditampilkan). Hal ini diduga menjadi penyebab menurunnya tingkat kesukaan konsumen disamping penyebab utamanya adalah menurunnya kadar amilosanya. Pada beras Tarabas bulan ke-1 masih sangat disukai, bulan ke-2 disukai, bulan ke-3 dan 4 sudah menjadi kurang disukai, serta bulan ke-5 menjadi tidak disukai. Seperti halnya pada beras Ciherang, pada beras Tarabas secara visual pada pada bulan ke-3 sudah banyak tumbuh kutu, disamping kandungan amilosanya juga menurun sejalan dengan lamanya penyimpanan.

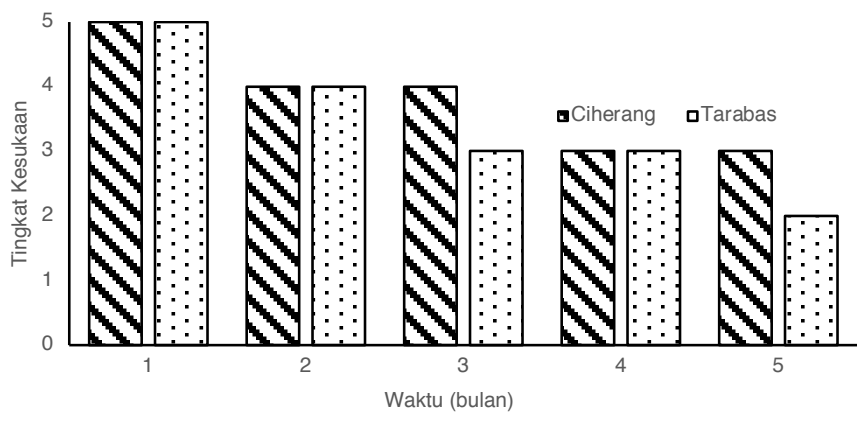

Figur 5. Hasil uji organoleptik beras Ciherang dan Tarabas

Secara visual, beras Tarabas berwarna putih dan berbentuk sedikit bulat dan dijual dengan harga menengah keatas, tetapi dalam waktu penyimpanan terjadi penurunan mutu lebih cepat dibandingkan dengan beras Ciherang. Beras dengan harga menengah keatas memiliki segmen pasar tersendiri, dengan waktu simpan hanya hingga 2 bulan dengan segmentasi kearah konsumen yang loyal (Minten et al, 2013). Disamping itu, penampakan fisik atau visualisasi menjadi daya tarik utama dalam pemilihan beras konsumsi. Umur simpan menjadi kriteria utama untuk dapat memenuhi kebutuhan nutrisi baik karbohidrat maupun kalori dari kandungan amilosa untuk layak dikonsumsi, sehingga konsumen dapat mengetahui secara tepat dan cepat kadar amilosa untuk memenuhi tingkat konsumsi kalori per hari dan dikombinasikan dengan sumber makanan lain baik yang rendah maupun tinggi kalori (Deaton and Dreze, 2009). Pemuaian butiran beras karena penyerapan air yang menyebabkan penurunan kekerasan yang spesifik untuk setiap varietas serta berkorelasi positif dengan kanungan amilosa $(\mathrm{Li} \mathrm{H}$ et al., 2016). Varietas Ciherang lebih banyak digunakan oleh petani karena lebih disukai konsumen, warna dan aromanya yang khas. Selain itu dengan harga jual termasuk kategori harga menengah, yang dapat menjangkau seluruh lapisan masyakarat.

\section{Proses Validasi}

Proses validasi merupakan satu cara untuk membuktikan bahwa persamaan matematika yang sudah dibentuk memiliki tingkat ketelitian yang bisa dipercaya. Jika persamaan matematika yang telah dihasilkan telah lolos tahap validasi, maka dinilai telah memiliki tingkat keabsahan yang baik, yang akhirnya dapat dipergunakan sebagai alat penduga pada deteksi mutu organoleptik beras. Pada penelitian ini proses validasi menggunakan metode MAPE (Mean Average Percentage Error), dimana jika nilai MAPE yang kurang dari $5 \%$, memiliki status pendugaan sangat tepat, sedangkan antara 5 sampai $10 \%$ dinilai sebagai pendugaan yang tepat, dan jika MAPE lebih besar dari $10 \%$, maka pendugaan dinilai tidak tepat. 
Berdasarkan hasil validasi, pendugaan kadar amilosa beras Ciherang berdasarkan karakteristik nilai B memiliki nilai MAPE sebesar $1,72 \%$, yang menunjukkan bahwa persamaan matematik yang telah diperoleh dinilai sangat tepat untuk menduga kadar amilosa, sedangkan untuk pendugaan beras Tarabas memperoleh nilai MAPE yang lebih besar, yaitu sebesar $8,39 \%$ (data tidak ditampilkan), yang keduanya memioliki nilai dibawah $10 \%$.

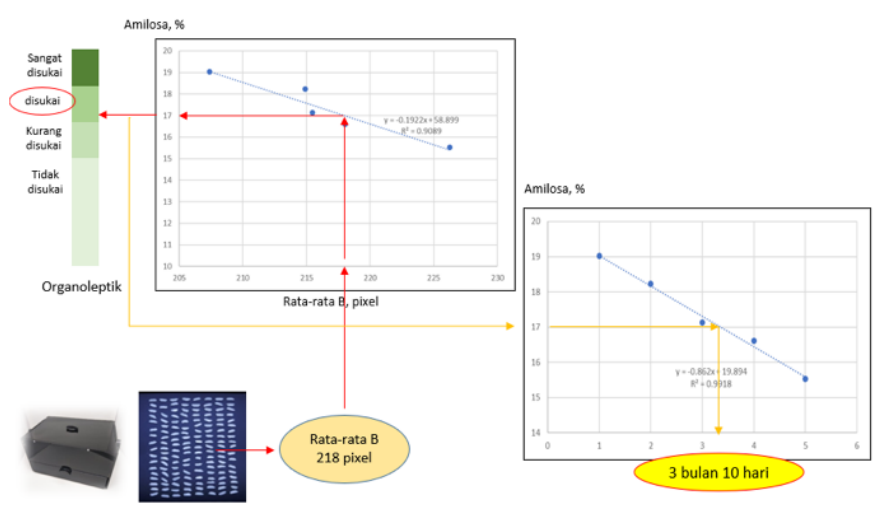

Figur 6. Mekanisme kerja deteksi cepat organoleptik beras
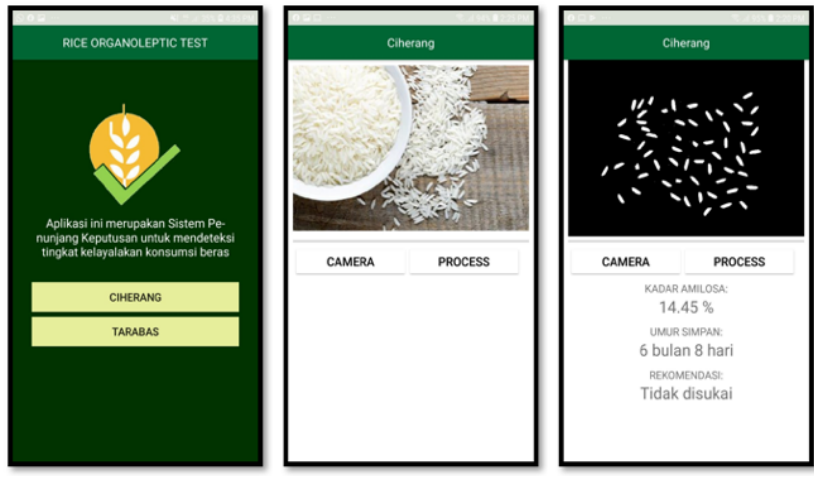

Figur 7. Tampilan antar muka aplikasi deteksi cepat organoleptik beras pada sistem Android

\section{Aplikasi Deteksi Mutu Organoleptik Beras}

Aplikasi deteksi cepat organoleptik beras, sistem kerjanya dilakukan berdasarkan pada pemanfaatan persamaan matematika pada hubungan antara kandungan amilosa beras dan karakteristik nilai $B$, serta persamaan matematika pada perubahan kandungan amilosa beras selama penyimpanan. Setiap piksel pada citra warna mewakili kombinasi 3 warna dasar yaitu merah, hijau dan biru (RGB) dimana setiap warna dasar, menggunakan penyimpanan 8 bit yang setara dengan 1 byte dengan nilai maksimum yaitu 255. Berdasarkan perhitungan ini 1 piksel warna diwakili oleh 3 byte (Aris et al., 2016). Sebagai contoh, jika pada hasil pemindaian citra beras Ciherang diperoleh nilai B sebesar 218 pixel, maka dugaan kandungan amilosanya sebesar $17 \%$. Nilai amilosa yang diperoleh tersebut kemudian disandingkan dengan nilai organoleptiknya. Dalam hal ini, kondisi beras masuk dalam kategori disukai. Setelah itu nilai amilosa yang sudah diperoleh tersebut dimasukkan ke dalam persamaan matematik perubahan kandungan amilosa beras selama penyimpanan. Sistem ini bekerja secara cepat dengan menggunakan Android dengan syntax berbasis Java. Sistem kerja android tersebut seperti ditunjukkan pada Figur 6 .

Penampilan aplikasi deteksi cepat organoleptik beras yang sudah diinstalkan pada smartphone ditunjukkan pada Figur 7. Tampilan pertama berupa halaman untuk memilih varietas beras apa yang diuji, selanjutnya halaman berikutnya adalah halaman tempat melakukan deteksi cepat mutu organoletik berasnya. Kemudian dapat dilihat juga tampilan antar muka aplikasi deteksi cepat organoleptik beras pada halaman selanjutnya.

\section{Kesimpulan}

Karakteristik citra beras selama penyimpanan dapat dilihat dengan jelas pada perubahan nilai Blue, baik untuk beras Ciherang maupun Tarabas. Nilai Blue ini berkorelasi positif terhadap perubahan kadar amilosa dan lamanya penyimpanan. Aplikasi deteksi cepat organoleptik beras dilakukan dengan mengakomodasi perubahan citra, amilosa, dan mutu organoleptiknya dan telah menunjukkan fungsi yang baik.

\section{Ucapan Terimakasih}

Artikel yang ditulis merupakan bagian dari Penelitian yang berjudul "Pengembangan Teknologi Pengemasan, Penyimpanan dan Deteksi Cepat Mutu Beras Mendukung Pemberlakuan Regulasi Perberasan Nasional" dengan ketua tim riset Mulyana Hadipernata dan dukungan pendanaan dari Balai Besar Penelitian dan Pengembangan Pascapanen, Badan Penelitian dan Pengembangan Pertanian, Kementerian Pertanian melalui DIPA tahun 2019.

\section{Daftar Pustaka}

Ahmed, J., Jafri, M.N., Ahmad, J., Khan, M.I. 2005. Design and implementation of a neural network for real-time object tracking. World Academy of Science, Engineering and Technology 6:209-212. DOI:10.5281/zenodo.1061154.

Aris, B.S., Suma'inna, Maulana, H. 2016. Pengenalan citra wajah sebagai identifier menggunakan metode Principal Component Analysis (PCA). Jurnal Teknik Informatika 9(2):166-175. DOI:10.15408/jti.v9i2.5608.

Blasco, J., Aleixos, N., Go'mez J., Molto, E. 2007. Citrus sorting by identification of the most common defects using multispectral computer vision. Journal of Food Engineering 83: 384-393. DOI:10.1016/j.jfoodeng.2007.03.027.

Blasco, J., Cubero, S., Gómez-Sanchís, J., Mira, P., Moltó, E. 2009. Development of a machine for the automatic sorting of pomegranate (Punica granatum) arils based on computer vision. Journal of Food Engineering 90: 27-34. DOI:10.1016/j.jfoodeng.2008.05.035.

Bhattacharya, K.R. 2011. Rice Quality, A Guide to Rice Properties and Analysis. Woodhead Publishing series in Food Science, Technology and Nutrition 
219. Woodhead Publishing Limited, Cambridge, UK.

Cabaret, L., Lacassagne, L., Oudni, L. 2014. A Review of world's fastest connected component labeling algorithms: speed and energy estimation. Proceedings Conference on Design and Architectures for Signal and Image Processing. DOI:10,3390/jlpea8010007.

Chen, S., Xiong, J., Guo, W., Bu, R., Zheng, Z., Chen, Y. 2019. Colored rice quality inspection system using machine vision. Journal of Cereal Science 88:8795. DOI:10.1016/j.jcs.2019.05.010.

Deaton, A., Dreze, J. 2009. Food and nutrition in India: Facts and interpretations. Economic and Political Weekly 44(7):42-65.

Effendi, M., Fitriyah, Effendi, U. 2017. Identifikasi jenis dan mutu teh menggunakan pengolahan citra digital dengan metode jaringan syaraf tiruan. Jurnal Teknotan 11(2):67-76). DOI:10.24198/jt.vol11n2.7.

Gilbert, R.G., Witt, T., Hasjim, J. 2013. What is being learned about starch properties from multiple-level characterization. Cereal Chemistry 90(4):312325. DOI:10.1094/CCHEM-11-12-0141-FI.

Hadipernata, M., Hidayah, N., Nugraha, S. 2020. Determination of rice expiration time based on microbiological contaminant. IOP Conference Series Earth and Environmental Sciences 518:15. DOI:10.1088/1755-1315/518/1/012053.

Hung, J.S., Chen, S.L. 2012. An optical automatic measurement method for the moisture content of rough rice using image processing techniques. Computers and Electronics in Agriculture 85:134139. DOI:10.1016/j.compag.2012.04.012.

Kuo, T.Y., Chung, C.L., Chen, S.Y., Lin, H.A., Kuo, Y.F. 2016. Identifying rice grains using image analysis and sparse-representation-based classification. Computers and Electronics in Agriculture 127:716-725. DOI:10.1016/j.compag.2016. 07.020.

Li, H., Prakash, S., Nicholson, T.M., Fitzgerald, M.A., Gilbert, R.G. 2016. The importance of amylose and amylopectin fine structure for textural properties of cooked rice grains. Food Chemistry 196:702-711.

DOI:10.1016/j.foodchem.2015.09.112.

Minten, B., Murshid, K.A.S., Reardon, T. 2013. Food quality changes and implications: Evidence from the rice value chain of Bangladesh. World Development DOI:10.1016/j.worlddev.2012.06.015.

Narendra, V.G., Hareesh, K.S. 2010. Prospect of computer vision automated grading and sorting systems in agricultural and food products for quality evaluation. International Jounal of Computer Applications 1(4):1-9. DOI:10.5120/111-226.

Neelamegam, P., Abirami, S., Priya, K.V., Valantina, S.R. 2013. Analysis of rice granules using image processing and neural network. IEEE Conference: 879-884. DOI:10.1109/CICT.2013.6558219.

Nuriana, A, Aini, N., Karseno, K. 2019. Formulasi Breakfast Meal Flakes dari Tepung Suweg dan Stabilized Rice Bran Menggunakan Metode Respon Permukaan. Jurnal Aplikasi Teknologi Pangan 8(2). DOI:10.17728/jatp.3952.

Pattel, K.K., Kar, A., Jha, S., Khan, M. 2012. Machine vision system: a tool for quality inspection of food and agricultural products, Journal of Food Science and Technology 49:123-141. DOI:10.1007/s13197-011-0321-4.

Wibawa, I.P.M.P., Gunadnya, I.B.P., Wijaya, I.M.A.S. 2019. Pendugaan umur simpan benih padi (Oryza sativa L) menggunakan metode ASLT (Accelerated Shelf Life Testing) dengan pendekatan model kadar air kritis. Jurnal Biosistem dan Teknik Pertanian 7(2):228. DOI:1024843/JBETA.2019.v07.i02.p02.

Permentan 31. 2017. Peraturan Menteri Pertanian Tentang Kelas Mutu Beras. 31 Agustus 2017.

Putranto, B.Y.B., Hapsari, W., Wijana, K. 2010. Segmentasi warna citra dengan deteksi warna HSV untuk mendeteksi objek. Jurnal Informatika 6(2):1-14. DOI: 10.21460/inf.2010.62.81.

Robyt, J.F. 2008. Starch: Structure, properties, chemistry, and enzymology. Glycoscience:14371472. DOI: 10.1007/978-3-540-30429-6_35.

Sari, A.R., Martono, Y., Rondonuwu, F.S. 2020. Identifikasi kualitas beras putih (Oryza Sativa L.) berdasarkan kandungan amilosa dan amilopektin di pasar tradisional dan "selepan" Kota Salatiga. Titian IImu: Jurnal IImiah Multi Sciences 12(1):2430. DOI:10.30599/jti.v12i1.599.

SNI 6128:2015. Kelas Mutu Beras. Badan Standardisasi Nasional, Indonesia.

Somantri, A.S. 2010. Menentukan klasifikasi mutu beras dengan menggunakan teknologi pengolahan citra digital dan jaringan syaraf tiruan. Jurnal BSN 12(3):162-173. DOI:10.31153/js.v12i3.154.

Somantri, A.S., Miskiyah., Nugraha, S. 2015. Jurnal Standardisasi Volume 17(1):47-58. DOI:10.35724/mustek.v7i2.908.

Supriyadi, E., Basuki, A., Sigit, R. 2020. Deteksi kualitas beras menggunakan segmentasi citra berdasarkan pecahan bulir dan sebaran warna. Jurnal Informatika \& Rekayasa Elektronika 3(1):20-29. DOI:10.36595/jire.v3i1.210.

Syamsiah, M., Masliah, M. 2019. Identifikasi kadar amilosa beras pandanwangi dari tujuh kecamatan di Kabupaten Cianjur. Agroscience 9(2):130-136.

Timmermans, A.J.M. 1998. Computer vision system for online sorting pot plant based on learning techniques. Acta Horticultura: 421:91-98. DOI:10.17660/ActaHortic.1998. 421.8.

Vanna, T., Bundit, L. 2007. Changes in quality of rice (Oryza sativa L.) cv. Khao Dawk Mali 105 during storage. Journal of Food Biochemistry 31(3):415425. DOI:10.1111/j.17454514.2007.00125.x. 
Wardani, N.P.P.P., Adiputro, I.G.K., Suardana, A,A,K. 2020. Efektivitas repelensi serbuk daun pandan wangi (Pandanus amarylilifolius Roxb) terhadap kutu beras (Sitophilus oryzae L) pada beras merah (Oryza nivara). Jurnal Widya Biologi 11(1):30-40.

DOI:10.32795/widyabiologi.v11i01.568.
Wright, J., Yang, A.Y., Ganesh, A., Sastry, S.S., Ma, Y. 2009. Robust face recognition via sparse representation. Pattern Analysis and Machine Intelligence. IEEE Transaction on Pattern Analysis and Machine Intelligence 31 (2):210-227. DOI:10.1109/TPAMI.2008.79. 